\title{
ЭВОЛЮЦИЯ ВЕЩЕСТВЕННОГО СОСТАВА ВУЛКАНОГЕННО-ОСАДОЧНЫХ КОМПЛЕКСОВ КОЛЬСКОГО РЕГИОНА В АРХЕЕ
}

\author{
Козлов Н.Е. ${ }^{1}$, Мартынов Е.В. ${ }^{1}$, Фомина Е.Н. ${ }^{1}$, Сорохтин Н.О. ${ }^{3}$, Марчук T.С. \\ ${ }^{1}$ Геологический институт КНЦ РАН, Anamumbl,kozlov@geoksc.apatity.ru \\ ${ }^{2}$ Апатитский филиал ФГБОУ ВО Мурманский государственный технический университет, \\ marchuk@geoksc.apatity.ru \\ ${ }^{3}$ Институт океанологии имени П.П. Ширшова РАН, Москва,nsorokhtin@mail.ru
}

\section{Введение}

Дометаморфическая эволюция супракрустальных комплексов раннего докембрия Кольского региона длительное время привлекает внимание геологов-докембристов. Применение геологоструктурных, изотопно-геохимических методов в сочетании с геофизическими исследованиями позволили наметить этапы формирования древнейших структур региона $[1,7,17-19,21]$. При значительном разнообразии моделей эволюции информация о составе слагающих раннедокембрийские домены метаморфитов используется, к сожалению, крайне редко. Авторы настоящей работы, пытаясь ликвидировать данный пробел, достаточно давно обращаются к названной проблеме. В этой связи необходимо вспомнить первую подробную сводку [23] и одну из последних работ, посвященных данному вопросу [13]. В продолжение этих исследований в настоящей работе на основе данных о составе вещественно-структурных комплексов была изучена эволюция геодинамических режимов формирования метавулканитов архея Кольского региона.

Ранее при анализе состава метабазитов [13] был сделан вывод о последовательности формирования архейских комплексов северо-востока Кольского региона - от нижней части разреза Кейвкого домена, являющейся наиболее древней, к породным ассоциациям Лоттинского (аллареченский и нотозерский комплексы), Чапомского, Терского и частично Умбинского доменов, далее - КольскоНорвежского и Мурманский доменов и Беломорского подвижного пояса. На завершающем этапе архейской магматической активизации формировались супракрустальные комплексы ЛапландскоКолвицкого (низы разреза, сложенные гнейсо-амфиболитовыми толщами, так называемого Танапояса и основными гранулитами) и Титовско-Колмозерского зеленокаменных поясов.

\section{Материалы и методы}

В основу работы положено более 4500 полных силикатных анализов. В ходе исследований были систематизированы и сопоставлены материалы по геологии и вещественному составу раннедокембрийских комплексов. При проведении различного рода реконструкций исследовались метабазиты - метаультрабазиты, протолиты метаморфизованных аналогов которых распознаются наиболее надежно по их первичной природе и достаточно широко распространены в пределах большинства раннедокембрийских структур региона.

При реконструкции геодинамических режимов формирования протолитов метаморфических комплексов авторы исходили из того, что процессы эволюции Земли развивались нелинейно $[10,11]$, в связи с чем принцип актуализма нельзя напрямую применять при изучении геодинамических обстановок докембрия в полной мере, без внесения каких-либо поправок. С учетом этого, при проведении параллелей между докембрийскими и фанерозойскими породными комплексами генетически связанными с определенными режимами, в настоящей работе использовалось положение о специфичности докембрийского периода развития планеты, с одной стороны, и некоторой общности в характере реализации геодинамических обстановок на всем протяжении геологической истории, с другой, то есть о гомологичных рядах геодинамических режимов [9].

В работе дана оценка распространенности в исследуемых объектах тех или иных разновидностей пород, выделенных по петрогеохимическим особенностям состава с использованием методики А.А. Предовского [22]. С учетом того, что она, как, впрочем, и иные разработанные для этих целей методы других авторов, в ряде случаев не дает однозначного ответа на вопрос о первичной при- 
роде пород (речь идет о метаморфитах кислого состава), эта задача решалась в двух вариантах. Все породы, точки состава которых попали на реконструкционных диаграммах в поля перекрытия осадочных и магматических образований, были отнесены в одном из вариантов сопоставлений к первой, а в другом - ко второй из этих групп. Далее сравнивались закономерности, выявляющиеся при разных вариантах реконструкций. Авторы исходили из того, что все промежуточные решения будут находиться внутри этих крайних решений. Окончательный вывод о характере распространенности делался в случае совпадения закономерностей, выявленных для обоих вариантов.

Для реконструкции раннедокембрийских геодинамических режимов был разработан метод эффективней в сравнении с использованными авторами ранее $[12,16]$, описывающий вышеупомянутую нелинейность. Он заключается в следующем, вместо 10 петрогенных элементов $\left(\mathrm{SiO}_{2}, \mathrm{TiO}_{2}\right.$, $\mathrm{Al}_{2} \mathrm{O}_{3}, \mathrm{FeO}, \mathrm{Fe}_{2} \mathrm{O}_{3}, \mathrm{MnO}, \mathrm{MgO}, \mathrm{CaO}, \mathrm{Na}_{2} \mathrm{O}, \mathrm{K}_{2} \mathrm{O}$ ) используем 8 параметров химического состава, преобразуя параметры $\left(\mathrm{FeO}, \mathrm{Fe}_{2} \mathrm{O}_{3}, \mathrm{MnO}\right)$ в новый параметр $\Sigma \mathrm{FeO}$. Смещение объектов докембрия относительно эталонов фанерозоя в 8-мерном признаковом пространстве (объекты докембрия и эталоны фанерозоя представленые множествами фигуративных точек) мы описываем при помощи поверхности 2-го порядка, разделяющей объекты докембрия и фанерозоя. При этом критерием того, что эта поверхность является разделяющей, служит статистическая значимость отличия между множествами фигуративных точек каждого объекта с множествами проекций этих точек на вышеуказанную поверхность, а множества фигуративных точек объектов докембрия и фанерозоя расположены по разные стороны этой поверхности. Мы используем оптимальную разделяющую поверхность, для которой минимальная близость всей совокупности объектов к поверхности - максимальна.

При распознавании геодинамической обстановки в которой формировался изучаемый объект докембрия мы должны работать с совокупностями фигуративных точек для объектов докембрия и эталонов фанерозоя расположенных на построенной разделяющей поверхности. Последние позволяет использование различных мер близости для проекций фигуративных точек химических составов объектов докембрия и фанерозоя, а также оценки достоверности полученных результатов с использованием статистических критериев. Ввиду того, что распределение фигуративных точек объектов не соответствует ни одному из известных классических, мы использовали непараметрические критерии. В данном случае - критерий Пури-Сена-Тамуры, который устойчив относительно нарушение нормальности (и даже унимодальности) распределения изучаемых случайных величин, а также относительно наличия в сопоставляемых выборках аномальных наблюдений. Как было уже упомянуто, мер близости существует множество. Выбор одной из них затруднителен ввиду отсутствия научно обоснованных аргументов в чью или иную пользу. Поэтому мы использовали следующий прием. Проводим реконструкцию режима формирования исследуемого докембрийского объекта с использованием различных мер близости и сравниваем результаты. Совпадение решений для большинства использованных мер близости следует считать достоверным решением.

Необходимо также отметить, что, как показывает опыт проведения подобных работ, при реконструкции геодинамических условий формирования протолитов древнейших образований, получаемые результаты, как правило, неоднозначны. В связи с этим более корректным представляется использование информации о близости к тем или режимам в виде тенденций изменения этих характеристик во времени.

\section{Результаты и обсуждение}

В силу отмеченных в предыдущем разделе причин отнести геодинамическую обстановку формирования протолитов любого из исследованных комплексов к какому-либо одному конкретному типу не представляется возможным. В связи с этим наиболее корректным авторы посчитали описание тех или иных тенденций эволюции этих обстановок в рамках обозначенной выше последовательности. Результаты реконструкции обстановок формирования протолитов архейских комплексов Кольского региона, приведенные в таблице 1 демонстрируют отчетливо проявленную тенденцию смены режимов, по петрогеохимичесим характеристикам наиболее сходных с траппами, более близкими континентальным рифтам. На завершающем этапе формирования архейских ком- 
плексов наиболее отчетливо проявляется подобие с юными дугами. Данная ситуация представляется возможной, поскольку подобная геодинамическая эволюция в пределах одного региона, характеризующаяся разным соотношением плюмового и субдукционного магматизма, известна для более молодых комплексов центральной и восточной Арктики [8].

Таблица 1. Результаты реконструкции обстановок формирования некоторых комплексов докембрия.

\begin{tabular}{|c|l|l|l|l|l|l|l|}
\hline $\mathrm{n} / \mathrm{n}$ & \multicolumn{1}{|c|}{ Структуры } & \multicolumn{1}{|c|}{ TRAP } & \multicolumn{1}{|c|}{ KR } & JD & \multicolumn{1}{c|}{ RD } & \multicolumn{1}{c|}{ SD } & COX \\
\hline 1 & Лоттинский домен & $\underline{\mathbf{2 . 6 6 7 *}}$ & $\underline{3.198}$ & $\underline{3.042}$ & 3.864 & 3.430 & 4.002 \\
\hline 2 & Кейвский домен & $\underline{\mathbf{3 . 6 1 1}}$ & $\underline{4.021}$ & $\underline{4.075}$ & 4.174 & 4.022 & 5.014 \\
\hline 3 & Беломорский подвижный пояс & $\underline{2.549}$ & $\underline{\mathbf{2 . 2 7 0}}$ & $\underline{2.349}$ & 2.833 & 3.050 & 2.775 \\
\hline 4 & Кольско-Норвежский домен & $\underline{2.448}$ & $\underline{\mathbf{2 . 2 7 8}}$ & $\underline{2.308}$ & 2.791 & 3.265 & 2.781 \\
\hline 5 & Мурманский домен & $\underline{2.549}$ & $\underline{\mathbf{2 . 3 6 1}}$ & $\underline{2.371}$ & 3.074 & 3.145 & 3.144 \\
\hline 6 & Титовско-Колмозерский пояс & 3.555 & $\underline{\underline{3.284}}$ & $\underline{\underline{\mathbf{3 . 1 7 0}}}$ & 3.855 & 4.045 & $\underline{3.275}$ \\
\hline 7 & Лапландско-Колвицкий пояс & 2.535 & $\underline{\underline{2.135}}$ & $\underline{\mathbf{2 . 1 1 7}}$ & 2.675 & 2.982 & $\underline{2.435}$ \\
\hline
\end{tabular}

* «расстояния» докембрийских выборок до соответствующих эталонных (фанерозойских) групп, условно названные «коэффициентом близости». Чем меньше значения приведенных коэффициентов (жирным выделено), тем ближе сравниваемые объекты. Подчёркнутые цифры - значения минимального отличия, если они незначимо отличаются от ближайшего по величине значения, при выбранном уровне значимости $\alpha=0.05$. Жирным выделено значение минимального отличия. TRAP - траппы, KR - континентальные рифты, JD, RD, $\mathrm{SD}$ - юные, развитые и зрелые дуги соответственно, COX - срединно-океанические хребты.

При описании возможного направления развития древнейших комплексов Кольского региона сначала следует оговориться, что фундамент древнейших супракрустальных образований региона, по нашей схеме кейвских метавулканитов, нам неизвестен. Реконструкция геодинамических режимов формирования раннедокембрийских комплексов Кольского региона по составу основных пород низов разреза Кейвской структуры, показывает, что они были наиболее сходными с базальтами трапповых формаций (табл. 1). Таким образом, можно полагать на ранних этапах становления супракрустальных комплексов Кольского региона развитие рассеянного рифтогенеза в пределах древнейшей коры, имеющей, как минимум, черты континентальной. Возможно, реликты этой коры обнаружены в ядрах цирконов в ходе исследований последних десятилетий $[2,20,24]$. В пределах Кейвского домена прослеживается более сложная, в сравнении с другими доменами региона, многостадийная история становления континентальной коры, что отмечалось нами ранее на основе анализа региональных геолого-геофизических данных [14]. С трапповыми формациями наиболее сходны и метабазиты Лоттинского домена.

Полученные данные, с учетом информации о формирования наиболее древнего ядра Кольского протоконтинента на северо-востоке региона и его наращивании далее в западном и юго-западном направлении, позволяют предложить следующую модель развития породных ассоциаций Кольского региона, наиболее согласованную со сведениями о вещественном составе метаморфитов. Подчеркнем, что она базируется как на новых данных, так и на материалах предыдущих исследований [13-15]. Началом формирования Кольской ГГО можно считать образование ее ядра, сложенного основными породами низов разреза Кейвского домена, следы вещества которого сохранились в виде основных пород патчервтундровской и лебяжинской свит. Это ядро наращивался в южном и юго-западном направлении образованиями, сформировавшими пояс (зону внутрикратонной активизации), сложенный супракрустальными породами Лоттинского, Чапомского, Терского и частично Умбинского доменов.

В западном направлении на следующем этапе шло формирование комплексов КольскоНорвежского домена. В ходе последующего объединения Кольской ГЗО и Карельской ГГО в единую Карело-Кольскую архейскую литосферную плиту происходило формирование супракрустальных комплексов Беломорского домена. Первично вулканогенные образования Мурманского домена, возможно, формировались не на первом этапе, а синхронно по времени с породными ассоциациями Беломорского домена. С учетом своеобразия состава пород Мурманского домена нельзя исключать того, что до ребольского этапа складчатости он развивался отдельно от остальной территории региона и был присоединен к другим доменам лишь на ранних его этапах. 
В неоархее все окружающие Кейвскую структуру домены были надвинуты на нее. При этом главной областью сноса для осадков Кейвской структуры являлись, по всей видимости, породные ассоциации Кольско-Норвежского домена, что и определило максимальное сходства состава слагающих их породных ассоциаций. Таким образом, Кейвы в неоархее представляли собой срединный массив. Принадлежность Кейвского домена к структурам такого типа, с которыми в фанерозое часто связаны месторождения углеводородов, позволяет лучше понять причины появления в кристаллических сланцах Кейв «метанового» графита [3, 4].

Далее, при взаимодействии Беломорского домена с доменами, расположенными к северовостоку от него шло формирование Лапландского протоостроводужного пояса, а при взаимодействии Кольско-Норвежского и Мурманского доменов - Титовско-Колмозерской шовной зоны, имеющей черты как островодужных, так и рифтогенных образований $[5,6]$. Эти черты проявились и в составе метабазитов - в Лапландском поясе они в большей степени сходны с вулканитами юных дуг, в то время как в Титовско-Колмозерской шовной зон наблюдается сдвиг в направлении вулканитов СОХ (табл.1, рис. 4).

\section{Заключение}

Выявленные тенденции изменения геодинамических режимов хорошо укладываются в общую схему последовательности формирования архейских комплексов, предложенную ранее, повышая степень ее достоверности.

Авторы подчеркивают предварительный характер предложенной схемы развития региона, которая нуждается в дальнейшем уточнении и согласовании со всем комплексом имеющейся по региону информации.

Работа выполнена в Геологическом институте Кольского научного центра РАН по государственному заказу №0231-2015-0007.

\section{Литература}

1. Балаганский В.В. Тектоностратиграфический террейн-анализ как основа для тектонического районирования // Геология и полезные ископаемые Кольского полуострова. Т.1. Геология, геохронология, геодинамика. Изд. КНЦ РАН. Апатиты. 2002. С. 44-56.

2. Бриджуотер Д., Скотт Д., Балаганский В.В. и др. // Природа раннедокембрийских метаосадков в Лапландско-Кольском поясе по результатам ${ }^{207} \mathrm{~Pb} / 206 \mathrm{~Pb}$ датирования единичных зерен циркона и $\mathrm{Sm}-\mathrm{Nd}$ изотопным данным по породам в целом ДАН. 1999. Т. 366. ‥ 5. С. 664-668.

3. Бушмин С.А., Глебовицкий В.А., Прасолов Э.М., Лохов К.И., Вапник Е.А., Савва Е.В., Щеглова Т.П. Происхождение и состав флюида, ответственного за метасоматические процессы в зонах сдвиговых деформаций тектонического покрова большие Кейвы Балтийского щита: изотопный состав углерода графитов //ДАН. 2011. Т. 438. № 3. С. 379-382.

4. Ветошкина О.С., Голубева И.И. «Метановый» графит в позднеархейских кристаллических сланцах (Кольский полуостров) // Вестник ИГ Коми НЦ СОРАН. № 4. 2012. С. 14-17.

5. Вревский А.Б. Петрология и геодинамические режимы развития архейской литосферы (на примере северо-восточной части Балтийского щита) Л.: Наука, 1989. 143 с.

6. Гавриленко Б.В., Никитин И.В., Зозуля Д.Р. Кудряшов Н. М., Петровский М. Н., Корсакова О. П., Галкин Н.Н. Геология, тектоника, возраст и металлогения архейской шовной зоны Колмозеро-Воронья, Кольский регион // Вест. МГТУ. 2002. Т. 5. 1. С. 43-60.

7. Глубинное строение, эволюция и полезные ископаемые раннедокембрийского фундамента ВосточноЕвропейской платформы: Интерпретация материалов по опорному профилю 1-ЕВ, профилям 4В и ТАТСЕЙС: в 2 т. + комплект цветных приложений. М.: ГЕОКАРТ: ГЕОС. 2010. Т. 1. 408 с. +48 цв.вкл., Т. 2. 400 с. +32 цв. вКЛ. (РОСНЕДРА, РАН, ГЕОКАРТ).

8. Добрецов Н.Л., Верниковский В.А., Карякин Ю.В., Кораго Е.А., Симонов В.А. Мезозойскокайнозойский вулканизм и этапы геодинамической эволюции центральной и восточной Арктики // Геология и геофизика. 2013. Т. 54. № 8. С. 1126-1144.

9. Козлов Н.Е. Вещественный состав метаморфических комплексов высокобарных гранулитовых поясов и проблема формирования их протолитов (на примере Лапландских гранулитов). Автореф. докторск. дисс., С-Пб. ИГГД. 1995. 36 с. 
10. Козлов Н.Е., Мартынов Е.В., Иванов А.А. Черты петрогеохимических различий основных пород энсиалических и энсиматических комплексов (сравнительный анализ фанерозоя и докембрия) // Геохимия, № 6. 1999. С. 582-588.

11. Козлов Н.Е., Мартынов Е.В., Предовский А.А. Петрогеохимическая реконструкция природы метаморфических пород и геодинамических обстановок формирования их протолитов (новые подходы и ограничения) // Геология и геофизика. 1999. № 8. Т. 40. С. 1236-1244.

12. Козлов Н.Е., Мартынов Е.В., Сорохтин Н.О. Реконструкция обстановок формирования протолитов раннедокембрийских комплексов (новые подходы) // Вест. КНЦ РАН, 2013. № 2. С. 9-14.

13. Козлов Н.Е., Мартынов Е.В., Сорохтин Н.О., Марчук Т.С. Эволюция вещественного состава метабазитов раннего докембрия Кольского региона. Вест. МГТУ. Т. 17. № 2. 2014. С. 304-313.

14. Козлов Н.Е., Сорохтин Н.О., Глазнев В.Н., Козлова Н.Е., Иванов А.А., Кудряшов Н.М., Мартынов Е.В., Тюремнов В.А., Матюшкин А.В., Осипенко Л.Г. Геология архея Балтийского щита. Спб.: Наука, 2006. 329 с.

15. Козлов Н.Е., Сорохтин Н.О., Мартынов Е.В. Эволюция вещественного состава супракрустальных комплексов архея Кольского региона // Вест. Коми НЦ СО РАН. № 1. 2015. С. 7-11.

16. Мартынов Е.В. Реконструкция обстановок формирования протолитов метаморфических комплексов докембрия на основе статистического моделирования их характеристик по петрогеохимическим данным. Автореф. дисс. к.г.-м.н. СПб.: ИГГД, 1997. 21 с.

17. Минц М.В., Глазнев В.Н., Конилов А.Н., Никитичев А.П., Раевский А.Б., Седых Ю.Н., Ступак В.М., Фонарев В.И. Ранний докембрий северо-востока Балтийского щита: полеогеодинамика, строение и эволюция континентальной коры // Тр. ГИН РАН. Вып. 503. М.: Научный мир. 1996. 287 с.

18. Митрофанов Ф.П. Современные проблемы и некоторые решения докембрийской геологии кратонов. // Литосфера. 2001. № 1. С. 5-14.

19. Митрофанов Ф.П., Баянова Т.Б. Геохронология пород и процессов в архейских доменах Кольской провинции Балтийского щита // Минералогічний журнал. 2004. № 3. Т. 26. С. 33-39.

20. Мыскова Т.А., Бережная Н.Г., Глебовицкий В.А., Милькевич Р.И., Лепехина Е.Н., Матуков Д.И., Антонов А.В., Сергеев С.А., Шулешко И.К. Находки древнейших цирконов с возрастом 3600 млн. лет в гнейсах кольской серии Центрально-Кольского блока Балтийского щита (U-Pb, SHRIMP-II) // ДАН. 2005. Т. 402. № 1. С. 82-86.

21. Пожиленко В.И., Гавриленко Б.В., Жиров Д.В., Жабин С.В. Апатиты. Изд. КНЦ РАН. 2002.359 с.

22. Предовский А.А. Реконструкция условий седиментогенеза и вулканизма раннего докембрия. Л.: Наука. 1980.152 с.

23. Предовский А.А., Мележик В.А., Болотов В.И., Федотов Ж.А., Басалаев А.А., Козлов Н.Е., Иванов А.А., Жангуров А.А., Скуфьин П.К., Любцов В.В. Вулканизм и седиментогенез докембрия северо-востока Балтийского щита. Л.: Наука. Ленингр. отд-ние. 1987. 185 с.

24. Bayanova T.B., Kunakkuzin E.L., Serov P.A., Fedotov D.A., Borisenko E.S., Elizarov D.V. and Larionov A.V. Precise U-Pb (ID-TIMS) and SHRIMP-II ages on single zircon and Nd-Sr signatures from Achaean TTG and high aluminum gneisses on the Fennoscandian Shield / 32nd Nordic Geological Winter Meeting, Helsinki, Finland, 13-15 January 2016. Abs. Spec. P. 172. 